\title{
The consistency measure of hunan's electric power industry prosperity index
}

\author{
Chufan $\mathrm{Xu}^{1,2}$, and Ming Wen ${ }^{12, *}$ \\ ${ }^{1}$ State Grid Hunan Electric Power Company Ltd. Economic and Technical Reasearch Institute, \\ Changsha, China \\ ${ }^{2}$ Hunan Key Laboratory of Energy Internet Supply-demand and Operation, Changsha, China
}

\begin{abstract}
In view of the problem that the traditional electric power prosperity index lacks the support of the mixed frequency and multidimension data, a new consistency measure method is constructed, which uses time difference correlation analysis and principal component and consider the linkage of electric power and economy at the same time. Take the Hunan province for example, we set the pool of kinds of sectional electricity power consumption and other relatives data, use the method of principal component analysis to capture main character of electricity's change. The results show that the proposed consistency measurement model can describe the fluctuation characteristics of Hunan's Power Prosperity Index well. The model can be used for monitor the changes in the power industry status and promoting the policy-making about the adjustment of the energy-saving and environment-friendly structure.
\end{abstract}

\section{Introduction}

Electric power, as the "wind vane" of economic development, is closely related to economic development. Electrical data can more truly reflect the overall picture of economic development. According to the index used to evaluate China's GDP growth launched by the famous British political and economic magazine The Economist in 2010, electric power consumption can more truly reflect the overall picture of economic development. Compared with economic macro data, electricity consumption as the actual consumption is easier to verify, the statistical error is smaller, and it is more difficult to deliberately distort and falsify, so it can more accurately reflect the current economic situation.

Index construction method has always been one of the important means for domestic and foreign scholars to evaluate macroeconomic development ${ }^{[1-4]}$. Based on the synthetic index method, Fang ${ }^{[5]}$ uses financial, order, expectation and other indicators to construct China's macroeconomic leading index, so as to better judge the macroeconomic situation. Since the "Li keqiang index" proposed, electricity consumption has gradually been widely concerned. As an important part of Li keqiang index, industrial electricity consumption can better reflect the overall picture of industrial economic development compared with pure economic indicators, so it has become one of the important indicators for scholars to

Corresponding author: xflixian@163.com 
evaluate economic development. Shi et al. ${ }^{[6]}$ and Sun et al. ${ }^{[7]}$ introduced the prosperity index model in the field of economics into the field of electric power market analysis and prediction, took the electric power consumption of the whole society as the benchmark index. Liu et al. ${ }^{[8]}$ constructed an economic prosperity index based on electric power big data, which objectively reflects the economic operation status, assists in forecasting the trend of economic development, and achieves the goal of observing the economy from the perspective of electric power. Zhou et al. ${ }^{[9]}$ constructed an MF-MS-SW model capable of analyzing seasonal and monthly frequencies at the same time, and selected the antecedent, consistent and lagged mixing sample data composed of 21 indicators to construct China's mixed-frequency electric power prosperity index and warning signal system, so as to continuously evaluate and monitor China's electric power prosperity.

Most of the current studies build indexes through electric power data to predict electric power consumption, but ignore the role of electricity in predicting economy. To sum up, taking Hunan Province as an example, this paper introduces the prosperity analysis method into the electric power consumption market, constructs the electric power economic prosperity index, effectively monitors and warns the electric power in Hunan Province, and predicts the electric power economic situation in Hunan Province.

\section{Index selection and data processing}

The general influencing factors of power economic index selection and the operation characteristics of hunan province's macro-economy are considered comprehensively.In this paper, indicators are screened from both economic and electric aspects to construct the power economic indicator pool of Hunan Province, as shown in Table 1.

Table1. Alternative index pool of electric power economic index

\begin{tabular}{|c|c|}
\hline Index classification & name of index \\
\hline Consumption index & Hunan: Total retail sales of social consumer goods \\
\hline Investment indicators & $\begin{array}{l}\text { Hunan: Real estate development investment completed amount } \\
\text { Hunan: fixed asset investment }\end{array}$ \\
\hline Foreign trade indicators & $\begin{array}{l}\text { Hunan: Export amount } \\
\text { Hunan: Import amount }\end{array}$ \\
\hline Financial indicators & $\begin{array}{c}\text { Hunan: Local public finance revenue } \\
\text { Hunan: Local public finance expenditure } \\
\text { Hunan:CPI }\end{array}$ \\
\hline \multirow[t]{2}{*}{ Price indicators } & Hunan:RPI \\
\hline & Hunan:PPI \\
\hline \multirow{2}{*}{ Monetary Capital Index } & Hunan: Balance of local and foreign currency loans \\
\hline & Hunan: Balance of local and foreign currency deposits \\
\hline \multirow{6}{*}{ Industrial indicators } & Hunan: Iron ore production \\
\hline & Hunan: Raw iron production \\
\hline & Hunan: crude steel output \\
\hline & Hunan: Steel production \\
\hline & Hunan: Cement output \\
\hline & Industrial electricity consumption \\
\hline \multirow{2}{*}{$\begin{array}{l}\text { Power data of key } \\
\text { industries }\end{array}$} & $\begin{array}{c}\text { Electricity consumption for smelting of black metal and rolling } \\
\text { processing industry }\end{array}$ \\
\hline & Electricity consumption of non-metallic mineral products industry \\
\hline
\end{tabular}


National indicators
Electricity consumption of chemical raw materials and chemical products manufacturing industry

Electricity consumption of non-ferrous metal smelting and rolling processing industry

Transportation, electrical, electrical equipment manufacturing electricity consumption

Electricity consumption in the production and supply of electric power and heat industry

Macroeconomic climate index: the consensus index

Macroeconomic climate index: the leading index

Macroeconomic climate index: lag index

Export amount

fiscal expenditure

M2: on year-on-year basis

To determine the leading, consistent or lag time difference relationship of different indicators on the macro economy, it is first necessary to choose a benchmark reference index, as the standard to judge the nature of other indicators, as well as to test the results. When developing the monthly power economic index, we adopted the year-on-year growth rate of industrial added value as the benchmark index.

\section{Empirical results}

Time Difference Correlation analysis is a common method to verify the relationship among precedence, consistency and lag of time series by correlation coefficient. $\mathrm{Y}=\left(\mathrm{y}_{1}, \mathrm{y}_{2}, \cdots, \mathrm{y}_{\mathrm{n}}\right)$ as a benchmark, $\mathrm{X}=\left(\mathrm{x}_{1}, \mathrm{x}_{2}, \cdots, \mathrm{x}_{\mathrm{n}}\right)$ as the selected indicator, $\mathrm{r}$ is the Correlation Coefficient, so

$$
r_{l}=\frac{\sum_{t=t^{\prime}}^{T_{l}}\left(x_{t+l}-\bar{x}\right)\left(y_{t}-\bar{y}\right)}{\sqrt{\sum_{t=t^{\prime}}^{T_{t}}\left(x_{t+l^{-}}-\bar{x}\right)} \sum_{t=t^{\prime}}^{T_{l}}\left(y_{t}-\bar{y}\right)^{2}}, l=0, \pm 1, \pm 2, \ldots, t^{\prime}=\left\{\begin{array}{c}
1, \quad l \geq 0 \\
1-l, l<0
\end{array}\right\}
$$

In the formula, $\mathrm{L}$ is called the time difference or the delay number, representing the advance period or the lag period. When 1 takes a negative number, $L$ is ahead; when 1 takes a positive number, $\mathrm{L}$ is behind; 1 is the maximum dela. $\mathrm{T}_{1}$ is the number of data after the data collection. In this paper, the data of the index pool is converted into the relative value data of the same month, and the Correlation Coefficient between the benchmark index and the index pool is calculated. When the number of lag period is greater than $3, \mathrm{x}$ lag $\mathrm{y}$ index is denoted; When the lag is less than $-3, \mathrm{X}$ is ahead of $\mathrm{Y}$; When the lag period number is [$3,3], \mathrm{x}$ and $\mathrm{Y}$ are synchronized. In this part, the Correlation Coefficient of time difference in 20 periods of time lag is calculated, and the Correlation Coefficient of time difference of each index in the index pool is obtained.

The Correlation Coefficient of time difference with industrial value added in the same month was less than 0.3, including the amount of real estate development investment in Hunan Province, the electricity consumption of chemical raw materials and chemical manufacturing in Hunan Province, and the national fiscal expenditure. There are 24 indexes with time difference Correlation Coefficient above 0.3, among which 9 indexes with Correlation Coefficient above 0.3 and delay period number between $(-3,3)$ are consistent indexes, The number of delay periods below-3 was 7, which was identified as the leading indicator.There were 11 delay periods with more than 3 , which were the index of delay. This paper mainly constructs the power economic index based on principal component analysis. Firstly, the data are standardized, and then based on the standardized power and economic indicators, the number of components is screened by principal component 
analysis, and the power economic index of Hunan Province is calculated. The following figure shows the consistency index of Hunan electric power economy. The leading index and the lagging index is the same.
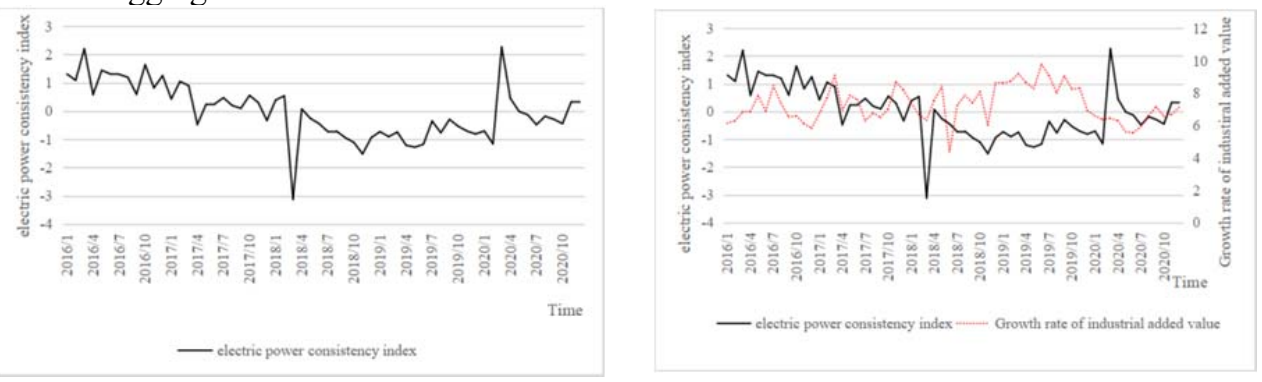

Fig. 1. Hunan Electric Power Economic consistency index.

Compare the constructed Hunan Electric Power Economic consistency index with the growth rate of industrial added value in Hunan Province, as shown in Fig.1. The growth rate of industrial added value in Hunan Province is roughly the same as that of Hunan Electric Power Economic consistency index. In addition to April 2018, Hunan Province was affected by the effect of the Spring Festival and the unsealing of the epidemic in April 2020. The consistency index can effectively monitor the economic development of Hunan Province.

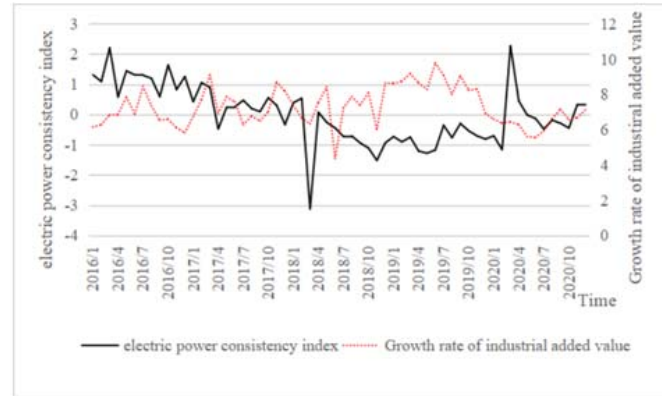

Fig. 2. Power economy consistency index and industrial added value trend of Hunan Province.

Compare the constructed Hunan electric power economy leading index with the growth rate of industrial added value in Hunan Province, as shown in Fig3. It can be found that from January 2016 to October 2016, the growth rate of industrial added value in Hunan Province is consistent with the leading index of electric power economy in Hunan Province; In November 2016, the leading index of Hunan electric power economy showed a peak, and the growth rate of leading industrial added value was 3 months; Meanwhile, the leading index of Hunan electric power economy in August 2017 is consistent with the growth trend of industrial added value in November 2017. Overall, the industrial added value of Hunan Province and the leading indicators of Hunan electric power economy show a fluctuating trend, but the leading indicators of power economy lead the industrial added value of Hunan Province for about three periods (three months). By constructing the leading indicators of Hunan electric power economy, we can effectively predict the economic growth trend of Hunan Province. 


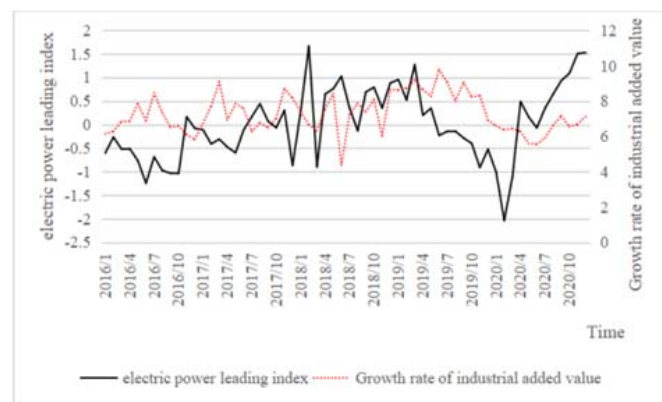

Fig. 3. Power economy leading index and industrial added value trend of Hunan Province.

\section{Conclusions}

According to the power economic index of Hunan Province, referring to the structure constructed by relevant scholars and Keqiang index, the driving force of economic development of Hunan Province and the power consumption of industrial industries with high power share are included in the index pool. Taking the year-on-year industrial added value of Hunan Province as the benchmark index, and according to the time difference correlation analysis, the leading index, consistent index and lagging index are selected in the index pool to construct the leading index, consistent index and lagging index of Hunan electric power economy. The constructed leading index of electric power economy leads the industrial added value for 3 months, and the constructed consistent index of electric power economy is synchronized with the industrial added value, The constructed index is tested. Therefore, the construction of Hunan electric power economic index can effectively evaluate the current economic development situation of Hunan Province.

\section{Acknowledgements}

State Grid Hunan Electric Power Co. , Ltd. Project Support (B616A221000J)

Science-Technology Innovation Pltaform and Talents Program of Hunan Provinve,China under Grant 2019TP1053

\section{References}

1. X.W. Li, M.X. Li, System engineering,33,12(2015)

2. Y. Hong, C.W. Ma, Statistics and decision making,36,13(2020).

3. J.S. Wang, Y.H. Ren, Research on quantitative economy and technical economy,38,2(2 021).

4. W.H. Liu, W.F. Wu, C. L. Yuan, J. H. Hou, Industrial technology and economy,40,1(2 020).

5. H.G. Fang, World research, 8(2021).

6. L. Shi, Y. Wang, Enterprise management, S2(2007).

7. R. H. Sun, M. Yang, H. K. Bai, Power big data,21,9(2008).

8. Y.J. Liu, K.H. Song, X . Wang, Telecommunications science,36,6(2020).

9. D.C. Zhou, J.J Chen, B. Liu, China power. 